\title{
Surface Roughness Analysis of Dental Ceramics Treated with Hydrofluoric Acid and Aluminum Oxide Jet
}

\author{
${ }^{1}$ Thiago Soares Porto, ${ }^{2}$ Mateus Rodrigues Tonetto, ${ }^{3}$ Camila Cruz Lorenzetti, ${ }^{4}$ Matheus Coelho Bandéca \\ ${ }^{5}$ Alvaro Henrique Borges, ${ }^{6}$ Sizenando Toledo Porto Neto, ${ }^{7}$ Edson Alves de Campos, ${ }^{8}$ Wellington Dinelli
}

\begin{abstract}
The aim of this study was to evaluate the surface roughness of 5 indirect restorative materials treated with hydrofluoric acid to $10 \%$, with aluminum oxide jet and a combination of both. The specimens was prepared with $10 \mathrm{~mm}$ in diameter and $2 \mathrm{~mm}$ thickness, divided into five groups: (1) Ceromer (Ceseadll-Kuraray), (2) Leucite crystals ceramics (IPS E mpressIIIvoclarforcasket), (3) glass ceramic with fluorapatite (IPS D. Sign-Ivoclar), (4) lithium disilicate ceramic (IPS Empress II-Ivoclar restorations), (5) ceramics (Cergogold-Degussa). For all groups were performed the controls, and the surfaces with the 3 types of treatment. For testing roughness used the rugosimeter Taylor/Hobson-Precision, model form tracerS V-C 525 high sensitivity. After confirmation of variance analysis with a significance level of $1 \%(p<0.01)$, there was equality between the average roughness of materials from groups 1,3 and 5 , and the group 2 was different from the others. It was also found that the ceramics of the group 5 behaved similar to group 4. However the lowest average roughness was observed in group 2 ceramic. In the evaluation between the types of treatment, the aluminum oxide jet and associations and blasting with hydrofluoric acid were similar, and different isolated hydrofluoric acid, and 3 types of treatmentsignificantly higher than the control group. All treatments promoted superficial alterations in all tested materials.
\end{abstract}

Keywords: Laboratory research, Hydrofluoric acid, Aluminum oxide.

How to cite this article: Porto TS, Tonetto MR, Lorenzetti CC, Bandéca MC, Borges AH, Neto STP, de Campos EA, Dinelli W. Surface Roughness Analysis of Dental Ceramics Treated with Hydrofluoric Acid and Aluminum Oxide J et. World J Dent 2014;5(1):1-5.

\section{Source of support: $\mathrm{Nil}$}

Conflict of interest: None

\section{INTRODUCTION}

Unquestionably the fact that, in recent decades, restorative dentistry is one of the most wide spread in dentistry, mainly

\footnotetext{
1,2 P hD Student, ${ }^{3}$ Master Candidate, ${ }^{4-8}$ Professor

1-3,6-8 Department of Restorative Dentistry, Faculty of Dentistry of Araraquara, São Paulo State University, São Paulo, Brazil

${ }^{4}$ Department of P ostgraduation in Dentistry, CEUMA University São Luiz, Brazil

${ }^{5}$ Department of Integrated Dental Sciences, University of Cuiabá, Cuiabá, Brazil

Corresponding Author: Matheus Coelho Bandéca, Professor Department of Postgraduation in Dentistry, Rua Operarios, 1457 Ponta G rossa, PR, Brazil, e-mail: mbandeca@ gmail.com
}

through research for innovations esthetic materials that can successfully replace the tooth structure. ${ }^{1}$ The great challenges, both in clinic procedures on how many surveys are adequate to achieve micromechanical retention of restorations and surface smoothness compatible with the dental tissues.

In the last decades has been used very esthetic restorative materials such as ceramics and polymers because are materials that exhibit excellent optical properties such as absorption, refraction, transmission and reflection of light, and good mechanical properties.

The surface treatment of materials allows uniting different structures or providing similar distribution of occlusal loads. ${ }^{1}$

A way to enhance the retention of esthetic restorative materials to the tooth is getting microretention by physical and chemical methods, and among them the aluminum oxide jet and hydrofluoric acid, complemented by silanization of the restorative material..$^{2-4}$

Various surface treatments have been used in ceramic to enhance the bond strength between resin cement and the inner surface of ceramics. $2,5-8$

The shear strength can be influenced by the bonding agent (silane) and etching. The silanization of porcelain associated with hydrofluoric acid treatment is able to determine consistent bond strength between resin cement and porcelain. ${ }^{5,9}$ A ccording Proenca, ${ }^{10}$ conditioning and silanization treatments are essential for bond of the resin to a lithium disilicate ceramic, regardless of the resin cement used.

Studies have al so detected that the best conditions of the porcelain and microretentions ceromer were obtained by treatment with an association of $10 \%$ hydrofluoric acid and aluminum oxide jet. ${ }^{9,11}$ B oth the hydrofluoric acid treatment how the use of sandblasting produce rough surfaces required for bonding, but the composition of the ceramic and the surface microstructure are important components to a substrate adhesion effective. ${ }^{12}$ This information is referenced in the literature by several studies developed within the context of creating microretention surface of esthetic material s. 3,4,13,14

Other studies have been developed to obtain information about the surface roughness of esthetic materials. M otro ${ }^{15}$ 
correlated the surface roughness with the ceramic color stability after different surface treatments. They concluded that the ceramics coloring may be related to changes in surface roughness after different surface treatments. Shimoe, ${ }^{16}$ after evaluate the influence of two surface treatments in indirect composite resins and zirconia, found an increase in surface roughness, therefore influencing the bond strength of zirconia with indirect composite studied.

A dhesive and mechanical retention to silica based on ceramics have been employed for bonding. A strong bond depends on the interconnection micromechanics created by surface roughness and by chemical bonding between the silane cement and ceramics. Currently there are techniques such as abrasion with diamond instruments rotating, abrasion with particles of aluminum oxide, hydrofluoric acid treatment, and even combination of techniques. The chemical composition and structural ceramics with high resistance, specifically alumina and zirconia, are not easily affected, methods requiring more aggressive mechanical abrasion to increase the surface roughness. ${ }^{2}$

Based on information from the literature, this study evaluated through rugosimeter, the effect of surface treatment of indirect esthetic materials, depending on some factors: M aterial (M ): (M 1) ceromer-II Cesead; (M 2) for IPS Empress II skull caps; (M 3) IPS D. Sign; (M 4) IPS Empress II restorations; (M 5) Cergogold; and surface treatment (T): (C) control; (T1) of $10 \%$ hydrofluoric acid; (T2) of al uminum oxide jet; (T3) combination of both.

\section{MATERIALS AND METHODS}

The materials used were:

- Ceromer (Cesead II-K uraray)

- Lithium Disilicate Ceramic melting at $920^{\circ} \mathrm{C}$ (IPS E mpress II-Ivoclar-Vivadent) for prosthesis casket to three el ements

- Glass Ceramic with fluorapatite and leucite crystals melting at $900^{\circ} \mathrm{C}$ (D. Sign- Ivoclar-Vivadent)

- Leucite Crystals Ceramic melting at 1075으 (IPS Empress II-Ivoclar-Vivadent) for indirect restorations (inlay, onlay, overlay and facets)

- Ceramics (Cergogold-Degussa) for prostheses casket until three elements.

\section{Preparation of Specimens}

The specimens were fabricated with the dimensions: $10 \mathrm{~mm}$ diameter and $2 \mathrm{~mm}$ thickness.

\section{Preparation Technical of Ceromer Specimens}

The specimens were prepared in stainless steel matrix, with the measures mentioned in the item ' $a$ '. Small layers of material were overlapped and polymerized for 90 seconds each in an oven light to the mark model UNIX s Kulzer, reaching a thickness of $2 \mathrm{~mm}$ - second manufacturer's specifications- after it was cured for 180 seconds. At the end, the specimen obtained tablet form.

\section{Technique of Obtaining Lithium Disilicate Ceramic (IPS Empress II), used to Casket Prostheses until Three Elements}

Initially wax buttons were obtained to using matrix of stainless steel. The wax buttons was included in the coating ring (special for Empress ceramics), to be brought to the oven at $850^{\circ} \mathrm{C}$ for 1 hour to complete el imination thereof.

In the inject oven ceramic Ivoclar model 2.9 the ring was placed at a temperature of $700^{\circ} \mathrm{C}$ and raised to $920^{\circ} \mathrm{C}$ (melting temperature of the ceramic) and $60^{\circ} \mathrm{C}$ for minute from $700^{\circ} \mathrm{C}$ initial. The temperature was maintained at $920^{\circ} \mathrm{C}$ for 15 minutes before the injection of the ceramic, remaining the same temperature for an indefinite period depending on the amount to be injected.

After removal of the ring from the oven, the porcelain was cooled to room temperature and opened the coating with aluminum oxide jet to avoid damaging the material. The specimen also obtained the same dimensions mentioned above.

\section{Preparation Technical of Specimens of Glass-ceramic with Fluorapatite and Leucite Crystals (D Sign)}

It was made a refractory of coating in pastille form in original dimensions and within the matrix was applied to the first ceramic layer and EDG burned in the oven at $900^{\circ} \mathrm{C}$ for 1 minute and 30 seconds. The temperature was gradually increased $60^{\circ} \mathrm{C}$ per minute until reaching $900^{\circ} \mathrm{C}$. Immediately after another layer was applied and the same procedure done so that there is compensation for the ceramic undergoes contraction.

\section{Technique of Obtaining Specimens of Leucite Crystals Ceramic (IPS Empress II), used for Indirect Restorations}

The technique used for the fabrication of specimens with this type of porcelain was the same as previously mentioned in item ' $a .2^{\prime}$ '. The only difference is the melting temperature, which in this case was of the order of $1075^{\circ} \mathrm{C}$.

\section{Technique of obtaining Specimens of Ceramic (Cergogold-Degussa)}

The technique used for the fabrication of specimens with this type of porcelain was the same as previously mentioned 
Surface R oughness Analysis of Dental Ceramics Treated with Hydrofluoric Acid and Aluminum Oxide J et

in item 'a.2'. The differences are located at the initial temperature was $600^{\circ} \mathrm{C}$ and raised to $60^{\circ} \mathrm{C}$ for minute until the melt temperature of approximately $980^{\circ} \mathrm{C}$.

\section{Surface Treatment of the Specimens}

\section{Etching with Hydrofluoric Acid to $10 \%$}

The surface of the specimens were etched with hydrofluoric acid $10 \%$ by time of 1 minute and then washed thoroughly with water to neutralize the acidic effect.

\section{Aluminum Oxide Jet—Bio Art}

The surface of the specimens was submitted to the al uminum oxide jet with equipment manufactured by Bio-A rt. Were used at 50 microns particle blasted for 10 seconds with a distance of $1 \mathrm{~cm}$ and pressure $60 \mathrm{~cm}$ libras/polegadas. The purpose of your job is to create micro-retentions on the surface of the tested materials.

\section{Etching with 10\% Hydrofluoric Acid and Aluminum Oxide Jet}

In this treatment, the surface of the test specimens were subjected to conditioning the association of $10 \%$ hydrofluoric acid and aluminum oxide jet, as described above.

\section{Establishment of the Experimental Groups}

Group 1: Ceromer (Cesead II-K uraray)-M 1

- Control (no treatment).

- Treated with $10 \%$ hydrofluoric acid.

- Treated with aluminum oxide jet.

- Treated with al uminum oxide jet and hydrofluoric acid $10 \%$.

Group 2: Lithium Disilicate Ceramics melting at $920^{\circ} \mathrm{C}$ (IPS Empress II) used for prosthesis casket until three elements- M 2.

- Control (no treatment).

- Treated with $10 \%$ hydrofluoric acid.

- Treated with aluminum oxidejet.

- Treated aluminum oxide jet and hydrofluoric acid $10 \%$. Group 3: G lass Ceramic with fluorapatite and leucite crystals melting at $900^{\circ} \mathrm{C}$ (D Sign-Ivoclar-Vivadent)-M 3 .

- Control (no treatment).

- Treated with 10\% hydrofluoric acid.

- Treated with aluminum oxidejet.

- Treated with al uminum oxide jet and hydrofluoric acid $10 \%$.

Group 4: Ceramic leucite crystals melting at 1075으 (IPS

Empress II), used for indirect restorations- M 4.

- Control (no treatment).

- Treated with 10\% hydrofluoric acid.
- Treated with aluminum oxide jet.

- Treated with aluminum oxide jet and hydrofluoric acid $10 \%$.

Group 5: Ceramics (Cergogold- Degussa)- M 5.

- Control (no treatment).

- Treated with $10 \%$ hydrofluoric acid.

- Treated with aluminum oxide jet.

- Treated with aluminum oxide jet and hydrofluoric acid $10 \%$.

\section{Surface Evaluation of the Specimens through Tests Roughness}

The equipment used in this study was rugosimeter Taylor/ Hobson-Precision, Model SV-C525 Form tracer high sensitivity. This equipment consists of a metal platform on which rests the specimens. It al so has an indent horizontal ly adjustable, coupled to a vertical rod which approach allows measuring tip surface roughness of the specimen. In the measurements, the measuring point adjustment was performed using a computerized automated device allowing, through sensitivity, adequate contact of the tip with the surface of the specimen. The slip tip measuring the surface of the specimen, was also triggered by another device attached to the computer program.

\section{RESULTS}

The original values of surface roughness ( $\mathrm{R}$ a) obtained are 80 measurements performed twice on the two axes of the specimens. Therefore four measures were made on each specimen. A nalysis of variance reveals that all values were significant at the $1 \%$ level, with $p<0.01$. The result of the analysis of variance shows that:

1. There was not effect of equal levels of factor material. It is conceded that the roughness variations in the context of various materials tested. In the check where variations roughness occurred for materials tested, applied the Tukey test, as follows in Table 1.

Based on the critical value of Tukey (0.12695), the Table 1 shows that there was equality (M 3) IPS-D.Sign (M 1) Cesead-II (M 5) Degussa. M oreover, the average found for (M 2) for IPS Empress casket was different from the others. It was also found that the ceramic (M 5) Degussa behaved similar to (M 4) IPS Empress for indirect restorations. However, it can be noted that the low est average roughness was observed in ceramics (M 2) for IPS Empress casket.

2. There was not equality of factor level effects of treatment. This means that for this factor are the averages of different roughness. So, the Tukey test was performed to compare their averages (Table 2). 
Table 1: Average roughness ( $\mathrm{R} a$ ) for materials (M)

\begin{tabular}{ll}
\hline Groups of materials (M) & Roughness mean (Ra) \\
\hline (M1)-Cesead-II & 1.33868 \\
(M2)-IPS-Casket & 0.88757 \\
(M3)-IPS-D-Sign & 1.37334 \\
(M4)-IPS-indirect restoration & 1.18288 \\
(M5)-degussa & 1.26813 \\
\hline
\end{tabular}

Table 2: Average roughness ( $R$ a) for surface treatment $(T)$

\begin{tabular}{ll}
\hline Groups of surface treatment (T) & Roughness mean (Ra) \\
\hline (C)-C ontrol & 0.50197 \\
(T1)-Hydrofluoric acid & 1.07734 \\
(T2)-Aluminum oxide jet & 1.61257 \\
$\begin{array}{l}\text { (T3)-Aluminum oxide jet and } \\
\quad \text { hydrofluoric acid }\end{array}$ & 1.64860 \\
\hline
\end{tabular}

Similarly, based on Tukey critical value (0.10837) for treatment, it was found that the averages of (T2) jet aluminum oxide, (T3) jet aluminum oxide and hydrogen fluoride were similar and different of (T1) hydrofluoric acid. It was al so observed that the average corresponding to three types of treatment were considerably larger than that shown in the group (C) control group, a fact which shows that all treatments induced variations in the surfaces of the materials.

\section{DISCUSSION}

Regarding the materials tested, some significant differences were found between them in the context of surface roughness and should highlight the material IPS Empress II-casket (M 2) that showed lower roughness values. Probably this fact has occurred due to the different compositions of these materials. The literature shows porcelains based leucite crystals, lithium disilicate, fluorapatite, feldspar, alumina, zirconia and other components, and even the resin matrix and ceramic particles to ceromer. M oreover, they have also with characteristics of high and low melting point.

In 2003, B orges ${ }^{12}$ reported that the composition of the surface microstructure of ceramic and all-ceramic restorations is important components of an effective substrate adhesion. In general, the indirect esthetic materials involved had different levels of roughness and stickiness when subjected to surface treatment in several studies. ${ }^{4,11,12,17,18}$

The treatments also behaved differently. As was expected, the control group, which received no treatment, showed the lowest levels of roughness. This reflects the fact that all types of treatment used were able to promote significant changes in the surfaces of ceramic materials.
It was also found that the action of the aluminum oxide jet (T2) and al uminum oxide jet associated with hydrofluoric acid (T3) were those which provided greater rugosity in relation to hydrofluoric acid (T1) used alone.

The results are consistent with those obtained in other studies, which aimed to create microretentions on material surfaces using various types of cosmetic treatment. 13,14,19-25

In fact, one way to improve retention and bond strength of esthetic restorative materials is getting microretentions for physical and chemical methods: aluminum oxide jet and hydrofluoric acid supplemented for silanization of the restorative material, according to the information. ${ }^{5,22,26}$

The vast majority of the results found in the literature, are related to bond strength tests, also involving indirect esthetic restorative materials and surface treatments varied: hydrofluoric acid; ${ }^{12,27-30,33}$ aluminum oxide jet; ${ }^{12,31}$ combination of aluminum oxide jet and hydrofluoric acid, $^{32,33}$ in which the combination of the treatments mentioned conditioned best results.

M oreover, Stewart ${ }^{14}$ emphasized that the literature is unclear about which cement, ceramic surface treatment and bonding agent would be more appropriate to produce more lasting and high bond strength. In addition other information contained in the literature ${ }^{34-37}$ emphasize the need to use techniques or chemicals, or association between them to create microretention surfaces of esthetic materials, in order to obtain better bond strength.

\section{CONCLUSION}

With the analysis of the results it was concluded that:

- All treatments promoted superficial alterations in all tested materials.

- The materials tested showed different roughness: IPS Empress II-casket (M 2) show ed the lowest roughness values while the highest average was shown by IPSD. Sign (M 3), which behaved similar to ceromerCesead II ( M 1) and Cergogold (M 5).

- The highest levels of roughness were caused for the association aluminum oxide jet and hydrofluoric acid (T3) follow ed by the action of the jet of aluminum oxide (T2).

\section{CLINICAL SIGNIFICANCE}

The results of this study suggest the use of surface treatment of esthetic materials with hydrofluoric acid, aluminum oxide jet or combining both to create microretentions and consequently better bond strength. 
Surface R oughness Analysis of Dental Ceramics Treated with Hydrofluoric Acid and Aluminum Oxide J et

\section{REFERENCES}

1. Tonetto $M R$, Pinto SC, Rastelli A de N, Borges $A H$, Saad JR, Pedro FL, deA ndrade M F, B andéca MC. Degree of conversion of polymer-matrix composite assessed by FTIR analysis. J Contemp Dent Pract 2013;14(1):76-79.

2. Piascik JR, Swift EJ, Thompson JY, G rego S, Stoner BR. Surface modification for enhanced silanation of zirconia ceramics. Dent $M$ ater 2009;25(9):1116-1121.

3. Osorio $E$, Toledano M , Silveira BL, Osorio R. Effect of different surface treatments on In-Ceram A lumina roughness. A n A FM study. J Dent 2010;38(2):118-122.

4. Guarda GB, Correr AB, Gonçalves LS, Costa AR, B orges GA, Sinhoreti MA C, Correr-Sobrinho L. Effects of surface treatments, thermocycling, and cyclic loading on the bond strength of a resin cement bonded to a lithium disilicate glass ceramic. O per Dent 2013;38(2):208-217.

5. Chen JH, Matsumura $\mathrm{H}$, A tsuta $M$. Effect of etchant, etching period and silane priming on bond strength to porcelain of composite resin. Oper D ent 1998;23(5):250-257.

6. Panah FG, Rezai SM, A hmadian L. The influence of ceramic surface treatments on the micro-shear bond strength of composite resin to IPS Empress II. J Prosthodont 2008;17(5):409-414.

7. Sarabi N, Ghavamnasiri M, Forooghbakhsh A. The Influence of A dhesive Luting Systems on B ond Strength and Failure M ode of an Indirect Micro Ceramic Resin-based Composite Veneer. J Contemp Dent Pract 2009;(10)1:33-40.

8. Kara HB, Dilber E, Koc O, Ozturk AN, Bulbul M. Effect of different surface treatments on roughness of IPS Empress II ceramic. Lasers M ed Sci 2012;27(2):262-272.

9. Yavuz T, Dilber E, Kara HB, Tuncdemir AR, Ozturk NA. Effects of different surface treatments on shear bond strength in two different ceramic systems. Lasers M ed Sci 2012. [Epub ahead of print].

10. Proenca PJ, Erhardt M CG, Valandro LF, A ceves GG, Carmona $M V B$, Salmeron RDC, B ottino M A . Influence of ceramic surfasse conditioning and resin cements on microtensile bond strength to a glass ceramic. J Prosthet Dent 2006;96(6):412-417.

11. K iyan VH, Saraceni CHC, Silveira BL, A ranha A CC, Eduardo $C P$. The influence of internal surfasse treatments on tensile bond strength for two ceramic systems. O per Dent 2007;32(5):457-465.

12. Borges GA, Sophr AM, de Goes M F, Sobrinho LC, Chan $D C$. Effect of etching and air bone particle abrasion on the microstructure of different dental ceramic. J Prosthet D ent 2003; 89(5):479-488.

13. Canay S, Hersek N, Ertan A. Effect of different acid treatments on a porcelain surface. J Oral Rehabil 2001;28(1):95-101.

14. Stewart GP, J ain $P, H$ odges J. Shear bond strength of resin cements to both ceramic and dentin.J Prosthet Dent 2002;88(3):277-284.

15. M otro PFK, K ursoglu P, K azazoglu E. Effects of different surface treatments on stainability of ceramics. J Prosthetic Dent 2012; 108(4):231-237.

16. Shimoe S, Tanoue N, K usano K, O kazaki M, Satoda T. Influence fair-abrasion and subsequent heat treatment on bonding between zirconia framework material and indirect composites. Dental M aterials J ournal 2012;31(5):751-757.

17. Torres SM P, B orges GA, Spohr A M , Cury AA DB, Yadav S, Platt $J A$. The effect of surfasse treatments on the micro-shear bond strength of a resin luting agent and four all-ceramic systems. O per Dent 2009;34(4):399-407.

18. B rum R, M azur R, A Imeida J, B orges G, Caldas D. The influence of surfasse standardization of lithium disilicate glass ceramic on bond strength to a dual resin cement. O per D ent 2001;36(5): 478-485.
19. Blixt $M$, A damczak E, Lindén L A, O dén A , A rvidson K . B onding to densely sintered alumina surfaces: effect of sandblasting and silica coating on shear bond strength of luting cements. Int J Prosthod 2000;13(3):221-226.

20. Estafan D, M artin KU, Dussetschleger F, Estafan A . M orphological effects of surface treatments on ceramic restorative materials. A m J Dent 2000;13(1):35-38.

21. Gillis I, Redlich M. The effect of different porcelain conditioning techniques on shear bond strength of stainless steel brackets. A m J Orthod Dent 1998;14(4):387-392.

22. Jardel V, D egrange M, Picard B, D errien G. Surface energy of etched ceramic. Int J Prosthod 1999;12(5):415-418.

23. Ozcan M, Alkumru HN, Gemalmaz D. The effect of surface treatment on the shear bond strength of luting cement to a glassinfiltrated al umina ceramic. Int J Prosthod 2001;14(4):335-339

24. Peumans $M$, Van M eerbeek $B$, Yoshida $Y$, Lambrechts $P$, Vanherle G. Porcel ain veneers bonded to tooth structure: an ultramorphological FE-SEM examination of the adhesive interface, Dent M ater 1999;15(2):105-119.

25. Sant'A nna EF, M onnerat ME, Chevitarese 0 , Stuani M B Bonding brackets to porcelain - in vitro study. Braz Dent J 2002;13(3):191-196.

26. B ouschlicher M R, Cobb DS, Vargas M A. Effect of two abrasive systems on resin bonding to laboratory-processed indirect resin composite restorations. J Esthet Dent 1999;11(4):185-196.

27. A ttia A, Kern M. Fracture strength of all-ceramic crows luted using two bonding methods. J Prosthet D ent 2004;91(3):247-252.

28. Filho $A M$, Vieira $L C$, A raujo $E$, M onteiro J unior $S$. Effect of different ceramic surface treatments on resin microtensile bond strength. J Prosthodont 2004;13(1):28-35.

29. Della B onna A , A nusavice KJ , M echolsky JJ J r. Failure analysis of resin composite bonded to ceramic. Dent M ater 2003;19(8): 693-699.

30. Schmage P, N ergiz I, Hermann W, Ozcan M . Influence of various surface-conditioning methods on the bond strength of metal brackets to ceramic surfaces. A m J Orthod Dentofacial Orthop 2003;123(5):540-546.

31. Petridis H, Garefis P, Hirayama H, K afantaris N M, Koidis PT. B onding indirect resin composites to metal: part 2. Effect of all oy surface treatment on elemental composition of alloy and bond strength. Int J Prosthodont 2004;17(1):77-82.

32. Saygili G, Sahmali S. Effect of ceramic surface treatment on the shear bond strengths of two resin luting agents to all-ceramic materials. J Oral Rehabil 2003;30(7):758-764.

33. Oh W S, Shen C, A legre B, A nusavice KJ. Wetting characteristic of ceramic to water and adhesive resin. J Prosthet Dent 2002;88(6):616-621.

34. Quran FA, Haj-Ali R. Fracture strength of three all-ceramic systems: Top-Ceram compared with IPS-E mpress and In-Ceram. J Contemp Dent Pract 2012;13(2):210-215.

35. D anappanavar PM, N anda Z, B haskar M, G owd V, M olugu M, Reddy K A, Reddy RK, K umar M A. Comparative evaluation of resistance failure in nonprecious metal-ceramic restoration at the incisal edge with varying thickness under different application of Ioad: an in vitro study. J Contemp Dent Pract 2011;12(6): 434-440.

36. Zorba Y O, B ayindir Y Z, B arutcugil C. Direct laminate veneers with resin composites: two case reports with 5 -year follow-ups. J Contemp Dent Pract 2010;11(4):E 056-62.

37. B andeca M C, Tonetto M R, B arros ÉD, Pinto SCS, Firoozmand $L M$, de A ndrade $M F, C$ urySaad JR, M aia Filho EM, de Sousa Queiroz RC. Indirect resin onlay cemented with self-adhesive resin cement: a comprehensive clinical overview. World J Dent 2012;3(3):273-277. 